\title{
Written Error Feedback from Perception to Practice: A Feedback on Feedback
}

\author{
Reza Norouzian \\ Faculty of Languages and Literatures, University of Tehran, Tehran, I.R. Iran \\ Email: rnorouzian@gmail.com \\ Ali Akbar Khomeijani Farahani \\ Faculty of Languages and Literatures, University of Tehran, Tehran, I.R. Iran \\ Email: farahani@ut.ac.ir
}

\begin{abstract}
Several aspects of written error feedback contexts have been simply overlooked or have remained on the sidelines, partly due to controversies over its long-lasting efficacy. The few studies conducted on the subject, though, failed in imparting key factors at work. This study sought to take learners' and teachers' written feedback perceptions as well as teachers' actual feedback practices into account to judiciously inspect two major areas of written feedback contexts; firstly, examining potential areas of mismatch between teachers' and learners' perceptions of teachers' error feedback practices and secondly, discovering the possible misfits between teachers' perception of their feedback practices and their actual feedback performance. To this end, 60 participants including 45 students from English classes with a focus on writing and 15 of their teachers were selected and asked to separately fill in teacher and student comprehensive questionnaires. Then, at the end of the course, an actual error correction task was corrected by the teachers and finally, they were orally interviewed. The results indicated four certain mismatch areas between teachers' and learners' views on (1) teachers' manners of marking, (2) use of error codes, (3) awareness of error selection principle and (4) effectiveness of teachers' error feedback practices. Moreover, four conspicuous areas of misfits between teachers' perception of (1) their manners of error marking (comprehensive vs. selective), (2) manners of feedback provision (direct vs. indirect), (3) use of error codes (4) amount of errors selected and their actual feedback performance were found. The implications are discussed.
\end{abstract}

Index Terms - perception, written error feedback, comprehensive marking, selective marking, direct feedback, indirect feedback

\section{INTRODUCTION}

Unceasing debate over the short- and long-term effect of error correction on writing accuracy in ESL/EFL contexts has long molded and pervaded much of what we conceive of as feedback studies. Nonetheless, most seemingly engrossing studies in this sense have been founded upon comparing erratically myriad methods and conditions of error feedback provision which have barely yielded any viable outcomes. In contrast, the formation and dynamics of such contexts, i.e. the potential mismatches in perceptions and reflections of key sides of such synergy-developing exercises have not come under much close scrutiny. In truth, few studies have ventured to establish what, in practice, teachers do as to L2 written error correction, and what the teachers' and learners' perceptions and expectations of those error feedback practices in an EFL context are. This is the case while calls for application of teachers' perceptions have infinitely refueled a flurry of studies that pursue data-first approaches to error correction as opposed to theory-first methodologies based upon the Grounded Theory (for a fuller discussion on procedures see Glasser, 1967, 1978, 2001 and Glasser \& Holton, 2004). As such, perception studies appear to function a key role by sustaining such newly resurfaced ideologies and spurring feedback researchers on to insightfully embark on their data-first methods. Furthermore, studies of this nature enable language instructors to be aware of what and how students think and how they may react to EFL teachers' feedback maneuvers. Moreover, this awareness in turn helps EFL teachers better reformulate the logics behind their practices and provides the ground for more dynamic learning environments conducive to learners' improved motivation.

Throughout the feedback provision processes, as pointed out by some feedback specialists, some featured and incontext practices have not received due attention. Among them, some camps of scholars have alluded to the crucial role of teachers' having a feedback framework for specifying errors, use of error codes and manners of marking and feedback provision in pinpointing many qualitative and quantitative aspects of teachers' feedback methods. Against this backdrop, the present study has endeavored to delve deeper into the issue, as befits a matter of such pedagogical significance, engaging both teachers' and learners' perspectives while it further utilizes an actual error correction task taken from the participating students to discern if there is a sense of division between learners' and teachers' 
perceptions on teachers' written feedback and, to a certain degree, between teachers' perceptions of their error correction and their actual classroom performance.

A synthesis of theory and practice has implied that creating a coherent, accurate and extended piece of writing, to most EFL and ESL learners, is far from easy. As a matter of fact, learners need to be guided toward active use of the target language. One of the steps that teachers should take to do so is through providing an independent learning environment in which constructive feedback to learners can be reinforced as they progress. Although many technical and contextual variations in the provision of error feedback exist, all of which cannot be done justice to in the format of the present study, the most common error feedback types include:

- peer feedback, conferencing, teachers' comments (Muncie, 2000),

- taped commentaries (Hyland, 1990),

- computer-based response (Brandl, 1995; Warschauer et al., 1996),

- portfolios (Belanoff \& Dickenson, 1991; Purves et al., 1995; Hamp-lyon \& Condon, 2000).

In what follows, a historical synopsis of written error feedback and studies on perception of error feedback will be presented.

The history of error correction in L2 writing proves that it has undergone several shifts over the past three decades. From the mid 1970s to the mid 1980s, there was a great deal of research on L2 writing classrooms. Such attention to treatment of learners' errors gained strength by the prevailing learning theories of the time, namely behaviorism which called for the immediate treatment of learners' errors in order to prevent fossilization phenomenon (Brown, 2007). In contrast, from the mid 1980s to the mid 1990s few studies were conducted on the subject. This was, as Ferris (2003) maintained, rooted in "the prominence of the process-oriented writing paradigm in ESL writing classes at the time with its consequent de-emphasizing of sentence-level accuracy issues" (p.42). In addition, some contrasting views on the ineffectiveness of error correction-which are still widely in the air (see Truscott \& Hsu, 2008) - seem to be accountable for such a period of silence in the use of error correction (Semke, 1984; Robb, Ross, and Shortreed, 1986). It was probably viewed as ineffective as it has been the case elsewhere in the area of second language teaching akin to some of once-ruling L2 teaching methods. Conversely, when the process writing gained support as a feasible framework, some writing scholars made attempts to deal with students' problems in writing accuracy (Eskey, 1983; Horowitz, 1986; Reid, 1994). Advocates of such a process approach believed that by putting much emphasis on students' content (e.g. Caulk, 1994; Ferris 1995; Conrad \& Goldstein, 1999), the appropriate form would proceed gradually as it is the case with L1 acquisition (see Krashan, 1981; Zamel, 1982, 1985). But in the meantime, a mound of evidence bore out the idea that errors committed by L2 learners in the course of L2 writing could be improved by musing solely on L2 writing learners' ideas and writing processes and that learners' low level of accuracy must be culprit in many diverse writing milieus. Therefore, a fair number of studies were carried out to tackle such concerns in learners' writing (see Raimes, 1985; Ferris, 1995). Still in its third decade, further research showed that, although "unnecessary and out of vogue error correction is to some writing researchers, in the classroom, error correction is a real and urgent issue that commands teachers' attention" (Lee 2004, p.286). Moreover, L2 writing research has showed that in L2 writing classrooms learners conceive of error correction as an essential part to the quality of their writing (Cohen, 1987; Leki, 1991; Lee, 1997; Ferris \& Roberts, 2001).

Among all debates, teachers while treating students' errors, as Lee (2003) put it, should clarify whether:

- to correct or not correct errors

- to identify or not identify error types

- to locate errors directly or indirectly

There are a number of research studies indicating that providing students with indirect error feedback (i.e., highlighting errors without presenting the correct form) is more beneficial to learners' improvement than direct forms of it (Lalende, 1982; Frantzen, 1995; Ferris, 2003). However, there is also unfailing support for the use of direct error feedback in certain cases such as for:

- beginning-level students

- or when errors are "untreatable"

- and when teachers try to draw students' attention to some other error forms that need learners`correction (Ferris, 2003).

Nevertheless, more recently, among lots of issues regarding error correction, teachers' and students' perspectives toward it have taken the center stage. In a similar vein, new developments in educational psychology has notably contributed to the rise of perception studies by stressing the central importance of learners and their attitudes toward learning from a humanistic perspective. In the area of error correction studies, neglecting learners' or teachers' perceptions of the error feedback has always been a thought-provoking issue. There is research evidence to prove that L2 learners want error feedback and believe that they benefit from it (e.g. Leki, 1991; Radecki \& Swales, 1988; Lee, 2004; Montgomery \& Baker, 2007). Nonetheless, these studies as with studies on feedback efficacy were not flawless.

Cohen and Cavalcanti's (1990) investigation was an attempt to incorporate the three factors in the study. They made use of teachers' own perceptions of their work in providing students' with the necessary written feedback, students' perspective, and the real practices that take place within an L1 and EFL contexts of university and institute. Their study revealed strong relationship between teachers' perceptions of their own feedback practices and their real performance in 
different categories that they investigated namely mechanics, vocabulary, organization, content, and grammar, especially at the college level. In fact majority of students saw their teacher as a judge. But their findings were not generalizable by any means in that they included few number of subjects in the study, to be exact, three teachers and nine students. Furthermore, the study did not make clear if teachers knew that their perceptions of their error correction practices would be compared with their actual practices in the classroom context.

In Satio (1994) he struggled to examine learners' perceptions and teachers' views on error feedback in order to later find the areas of mismatch between the two. He chose 24 L2 learners from intermediate to advanced level to complete a questionnaire on their teacher current feedback practices. In addition, to ensure teachers' feedback practices some observations were conducted. Final conclusion was that learners needed and welcomed teacher personally providing feedback. But teachers of these courses, instead, had practiced other forms of error feedback that did not require teacher presence, like self- or peer correction. The weak point of Satio's work seems to be the observation part. In fact, teachers had only been evaluated based upon observations so there was not reported any precise and objective estimate of their feedback practices.

To sum, a much of the past studies on error feedback perception (also see Leki, 1991; Komura, 1999; Rennie, 2000 and Ferris and Roberts, 2001, to name but a few) in 1990s and early 2000s accentuated:

- The importance of linguistic accuracy in writing to the overall efficacy of being a second language writer.

- Vitality of teacher feedback on errors as an ingredient for students to improve the accuracy of their writing.

- Superiority of comprehensive error marking over selective error making.

- Higher value of indirect correction (errors marked and labeled by error types) to that of direct correction (teachers making the corrections for students).

Later in her study, Lee (2003) merely focused on L2 writing teachers' perspectives, practices and challenges regarding error feedback ignoring the other side of the aisle meaning learners. Secondly, it did not provide information as to what and how teachers in reality adopt such error correction. Lee (2004) gave learners a voice, taking their perceptions into consideration. But she did not use the same writing sample of the under-study participants in the study of teachers' actual practices; that is, she made use of an artificial piece of writing, which is a major problem with her study as it couldn't viably be indicative of teachers' measure of actual practices. In fact, albeit some studies called for new research on teachers' perceptions (e.g. Montgomery \& Baker 2007), others stuck to teachers' perspectives ignoring students' perceptions (e.g. Lee, 2003, 2008).

It is in this sense that attempts should be made to chart a broader understanding of how teachers' perceptions relate to both student perceptions and teachers' actual written feedback practices. Also, in many ways, further insights should be offered into and critical questions should be drawn out about how teachers' perspectives relate to the writing process.

Accordingly, the present study is designed to answer the following major research questions:

1. What are the mismatches between EFL learners' and EFL teachers' perceptions regarding teachers' error feedback practices?

2. What are the misfits between EFL teachers' perceptions of written feedback and their real practices in the classroom?

\section{METHODOLOGY}

\section{A. Participants and Sampling}

A total of 60 subjects including 15 male and female L2 teachers and 45 of their students at 3 usual levels of instruction (15 classes) from beginning to advanced courses with a focus on writing at the University of Tehran, the Faculty of foreign Languages and Literatures, building, no 3 and 3 other private language institutes (from district 6 of the city of Tehran) participated in this study willingly. Students' age ranged from 14 to 36 . The average number of students that enrolled in each class also fell within the range of 6 to 18 people. As to teachers, however, those who put more emphasis on the writing section of their books and paid more attention to keeping up with teachers' guide book were more preferable due to the correction guidelines suggested in the teachers' guide book. Teachers' age ranged from 22 to 39 mostly having a related degree in an English-related field such as TEFL (Teaching English as a Foreign Language), English translation and English literature. Still, other teachers had an unrelated degree in medical sciences and chemistry.

\section{B. Materials}

The study made use of the following materials:

- a teacher questionnaire

- an error correction task taken from the participating students

- a Persian translated student questionnaire (which went through back-translation to ensure precision)

- and an oral interview (treated as open-ended questions).

To ensure updated and validated questionnaires, Lee's (2004) questionnaires were used. Later thoughtfully designed changes were implemented to them and their reliability indices were computed. Also, through the pilot study, construct validity of the questionnaires were assured. Lee (2009) also used the shortened form of the same teacher questionnaire. 
Finally to standardize and therefore better ensure the validity of the error correction task, the correction task was double-checked and scrutinized for any possible misfit in determining standard number and category of potential errors.

\section{Procedures}

In order to investigate teachers' and learners' perspectives on the written error feedback, EFL instructors were requested to complete their own separate questionnaires in almost beginning of the semester. Then, after at least 4 to 6 writing papers were exchanged back and forth between teachers and students, student questionnaire was distributed and its data was garnered. On the teachers' questionnaire, they were asked about their teaching experience, educational backgrounds (recognition type questions), the quantity and type of error feedback practices on their students' writings on the average, correcting errors comprehensively (i.e.; correcting all of the learners' errors on a written assignment) or selectively (i.e.; teachers' random selection of students error types), do they make it directly or indirectly (as asked about in the questionnaires), their major principle for the selection of errors, their use of marking codes, the role of students and teacher relating error correction, and the amount of time they spend on marking students' writings. Care was taken not to plunge too soon in implementing correction task (time trap). Therefore, one session before the final exam, they marked a 2- line, 5-paragraph sample composition from one of the participating students at advanced levels (due to their higher ability to write more) and answered 4 enclosed questions of the error correction task, not to mention, students at beginning levels were only able to write a short one-paragraph writing due to their low level of language proficiency, thus a lesser umber of errors could possibly occur and teachers could not have been seriously challenged and therefore reveal their error correction behaviors. This later on was compared to their questionnaire data for further convergence in the data analysis process. Also, teachers were asked ten questions regarding their feedback practices in an oral interview about their perceptions and preferences in an oral interview session. In addition, students received the translated version of their questionnaire and were asked to complete it (Figure 1).

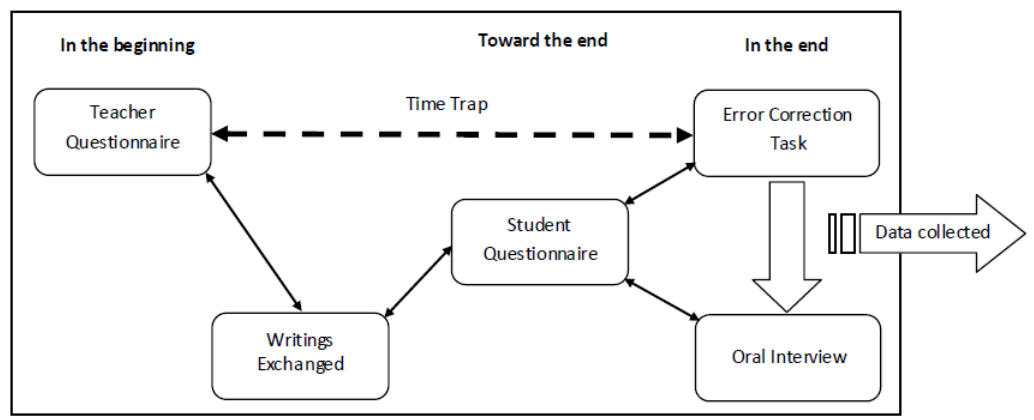

Figure1. Study design and data collection scheme

\section{Data Analysis}

To perform the statistical analyses, certain systematic measures were taken. (1) The first step was coding the questionnaire data. The coding framework for close-ended questions was straightforward as choices on both questionnaires ranged from "strongly agree to strongly disagree", based on the construct each question measures, Care was taken to assign these numerical codes according to the positivity or negativity of the construct under measurement as suggested by research methodologists (Dörnyei, 2003). (2) The second step was feeding the questionnaires data into SPSS. (3) Third step was checking the collected data for possible human errors while feeding data into SPSS. To do this last part more systematically, all data went through "data cleaning" process as suggested by Dörnyei's (2003) in analyzing questionnaires data. In his words, "Data cleaning involves correcting as many of errors and inaccuracies as possible before the actual analyses are undertaken" (p. 79).

Like any other psychometric (measurement) instrument a questionnaire must possess adequate reliability. To establish the reliability of the two questionnaires, Cronbach's Alpha was used, which is the measure of internal consistency. Result of the internal consistency test fell into "good" range of " 0.82 " for the teacher questionnaire and " 0.87 " for the student questionnaire.

Moreover, to standardize and therefore better ensure the validity of the error correction task, the task was doublechecked and scrutinized for any possible misfit in determining standard number and category of potential errors. This included identification, counting, categorization and marking of the errors on the task by four other English teachers' besides the researcher. The standard number of errors and their related categories in the error correction task, on different grounds was examined.

\section{RESULTS AND DISCUSSIONS}

As to the first and the second research questions frequency count analysis as with previous studies (Lee, 2004, 2009) was run and the inferential analysis based upon the areas of mismatch were presented. All descriptive statistics of both questionnaires data due to their size and comprehensiveness do not appear in this section. 


\section{A. Answer to the First Research Question}

To determine areas of mismatches between EFL learners' and EFL teachers' perceptions regarding teachers' error feedback practices; first, data from all areas of feedback perception and preferences common to both questionnaires coverage were collected underwent frequency count analysis, second, data were categorized, and compared and Finally areas of mismatch were identified and presented as with previous studies.

The results of the frequency count analysis of the areas of mismatch between perceptions of EFL teachers and EFL learners regarding teachers' error feedback determined five areas of mismatch including: (1) manners of marking (comprehensive vs. selective), (2) use of error codes, (3) students' awareness of teachers' error selection principle, (4) feedback responsibility and (5) effectiveness of teachers' error feedback practices. The results are categorized and presented below:

Comprehensive vs. selective marking

On the teacher questionnaire, the second question targeted teachers' perception of their error feedback practices regarding marking all potential errors in students written assignments (comprehensive error marking). There, a majority of $46.7 \%$ agreed (seven out of fifteen) and $20 \%$ (three out of fifteen) strongly agreed that they mark all students' error while marking their written assignments. In contrast, as to selective marking category which consisted of three questions subsumed under it (questions 4, 21, and 22), teachers expressed their views as follows: on question four which asked teachers' perception on whether they selectively mark students' errors $53.3 \%$ (eight out of fifteen) stated they disagreed and $6.7 \%$ (one out of fifteen) strongly disagreed on it. Further, when they were asked on question 21 that there is no need to mark students' written works selectively $67.7 \%$ disagreed. Here in fact teachers contradicted themselves. As to question 22 also teachers were asked if it is a "should" for them to selectively mark errors on students written works selectively. $53.3 \%$ disagreed on it and $13.3 \%$ were undecided on the issue.

On the other hand, on the student questionnaire, they were asked $66.7 \%$ disagreed their teachers' marking their errors comprehensively and a minority of $15.6 \%$ agreed all of their errors have been marked by their teachers (question 1). However $62.2 \%$ of students agreed teachers do not mark all of their errors (question 2). Tables 3 and 4 present teachers' and students' perceptions of teachers' practices on comprehensive and selective marking.

TABLE 3

TEACHERS' PERCEPTION OF THEIR MANNERS OF ERROR MARKING

\begin{tabular}{|l|l|}
\hline Teachers & Percentage (\%) \\
\hline Comprehensive & $66.7 \%$ \\
\hline Selective & $26.7 \%$ \\
\hline
\end{tabular}

TABLE 4

STUDENTS' PERCEPTION OF TEACHERS' MANNERS OF ERROR MARKING

\begin{tabular}{|l|l|}
\hline Students & Percentage (\%) \\
\hline Comprehensive & $15.6 \%$ \\
\hline Selective & $62.2 \%$ \\
\hline
\end{tabular}

Use of marking codes

On the general practice of marking codes, nine out of fifteen teachers, $73.3 \%$ which is a large majority of EFL instructors, on all three levels of instructions, rejected using error codes, that is, they strongly disagreed or disagreed on it and only $20 \%$ of them agreed on it (question 11). Further, 33.3\% disagreed on its helpfulness for students to guide them to correct their errors themselves. Moreover, $46.7 \%$ were undecided on this issue (question 25) and also on the clarity of it (questions 26), a majority of $64.7 \%$ were undecided on the fact that error codes should be clear and easy for students to understand and follow. Table 5 presents the percentage of teachers' perception of error codes.

TABLE 5

PERCENTAGE OF TEACHERS' PERCEPTIONS OF ERROR CODES

\begin{tabular}{|l|c|c|c|c|c|}
\hline Use of error codes (\%) & Strongly Disagree & Disagree & Undecided & Agree & Strongly Agree \\
\hline Using error codes & $13.3 \%$ & $60 \%$ & $6.7 \%$ & $20 \%$ & - \\
\hline Codes helpfulness & - & $33.3 \%$ & $46.7 \%$ & $20 \%$ & - \\
\hline Codes clarity & - & $6.7 \%$ & $73.3 \%$ & $20 \%$ & - \\
\hline
\end{tabular}

This is whereas, on the other side, almost $57.7 \%$ of the students expressed that their teachers use error codes to mark their written assignments (question 14) and $40 \%$ were undecided on the use of error codes by their teachers. Further, $40 \%$ rejected disability in understanding their teachers for later revisions (question 15) and 55.6\% agreed and 26.7\% strongly agreed that they to some extent can understand and follow their teachers' error codes (question 16), also 51.1\% of students rejected that they cannot completely understand their teachers' error codes (question 17). The result of the students' perception on the use of error codes is shown in Table 6 . 
TABLE 6

STUDENTS' PERCEPTION OF THE USE OF ERROR CODES

\begin{tabular}{|l|l|l|l|l|l|}
\hline Use of error codes (\%) & Strongly Disagree & Disagree & Undecided & Agree & Strongly Agree \\
\hline Using error codes & - & $2.3 \%$ & $40 \%$ & $51 \%$ & $6.7 \%$ \\
\hline $\begin{array}{l}\text { Inability in codes } \\
\text { understanding }\end{array}$ & - & $40 \%$ & $20 \%$ & $28.9 \%$ & $11.1 \%$ \\
\hline $\begin{array}{l}\text { Partial Ability } \\
\text { to Follow codes }\end{array}$ & - & - & $17.8 \%$ & $55.6 \%$ & $26.7 \%$ \\
\hline $\begin{array}{l}\text { Complete understanding } \\
\text { of codes }\end{array}$ & $11.1 \%$ & $40 \%$ & $28.9 \%$ & $20 \%$ & - \\
\hline
\end{tabular}

Here is where mismatch arises, generally there was a call from the learners' side for teachers to use error codes as they, with their current level of understanding of their teachers' coding framework, express a need for it—in spite of their incomplete or partial understanding of the codes, it proves, as mentioned earlier, learners generally take advantage of it while they are given opportunity to revise their written works and correct their errors for themselves - whereas majority of teachers at once rejected using any kind of error coding in marking students' written assignments. But it seemed other factors as putting more time and receiving more educational training and having a clear coding frame work to yield better results would help lessen the mismatch. So most definitely, these other relating factors need further research to prove effective (questions 11 and 14 respectively).

Awareness of type( $(s)$ of errors selected for marking

As EFL teachers, it has occurred to many of us on countless number of occasions where learners ask for whether, for instance, spelling errors are going to be marked by the teacher or not. The second area of mismatch was between EFL teachers' informing their students of the type(s) of selected errors for marking (question 30). 53.3\% of teacher agreed on the fact that they make their students aware of the type(s) of error they had selected to do the marking. Also $26.7 \%$ were undecided not knowing whether they do it or not and only a minority of $20 \%$ disagreed that they provide students with their error selection principle prior to marking students written assignments.

On student questionnaire a striking fact was revealed (question 4), as it could rationally be predicted experientially, data indicated, an absolute majority of $91.1 \%$ of the learners unanimously disagreed (80\% disagreeing and $11.1 \%$ strongly disagreeing over having any prior knowledge), that their teachers would have informed them of the any selection criteria. Table 7 presents the teachers' and students' perception of students' awareness of their error selection principle.

TABLE 7

TEACHERS' AND STUDENTS' PERCEPTIONS OF STUDENTS' AWARENESS OF THEIR ERROE SELECTION PRINCIPLE

\begin{tabular}{|l|l|l|l|l|l|}
\hline Awareness of Error selection Principle & Strongly Disagree & Disagree & Undecided & Agree & Strongly Agree \\
\hline Teachers & - & $20 \%$ & $26.7 \%$ & $53.3 \%$ & - \\
\hline Students & $11.1 \%$ & $80 \%$ & $8.9 \%$ & - & - \\
\hline
\end{tabular}

The mismatch here was more than clear; there was a total disregard on the part of teachers for not letting students know what aspects of writing were more important to them. This is also in contradiction with the already wellestablished fact in the language teaching that any moves inside the four walls of an EFL class must be purposeful. Further, as writing research moved from product to process writing, this shift should most certainly affect teachers' marking practices, therefore, this shift should have an imprint on students' writing and patterns and implications of responding to it. As a result, such a context of unawareness and mismatch between EFL learners and instructors can well diminish the positive and pedagogical influences of second and foreign language writing research.

Overall effectiveness of the existing feedback practices on students' grammatical accuracy

Finally where all these mismatches come down to is the effectiveness of such feedback provision methods on students' progress in their writing quality. Regardless of modern theories of language teaching, methods and rules, while teaching, most teachers resort to their experiences and already held assumptions.

On the teacher questionnaire, also it was asked, how these teachers evaluate their current feedback practices on student progress in grammatical accuracy in writing at the end of one semester (question 37). Here, 53.3.8\% of teachers stated that their students were making "some progress" on grammatical accuracy, also $33.3 \%$ of them considered their students as making "good progress" in the field of grammatical accuracy of their writings. And minority of $6.7 \%$ believed that their students' making "little progress". In addition, 6.7\% said on the questionnaire that their students were making "no progress" with their current feedback provision methods. Table 8 exhibits teachers' and students' views on students' grammatical progress regarding teachers' existing feedback practices.

TABLE 8

TEACHERS' AND STUDENTS' PERCEPTIONS ON THE EFFECTIVENESS OF TEACHERS' FEEDBACK PRACTICES

\begin{tabular}{|l|l|l|l|l|}
\hline Grammatical Progress & Good Progress & Some Progress & Little Progress & No Progress \\
\hline Teachers & $33.3 \%$ & $53.3 \%$ & $6.7 \%$ & $6.7 \%$ \\
\hline Students & $4.4 \%$ & $11.1 \%$ & $46.7 \%$ & $37.8 \%$ \\
\hline
\end{tabular}


Learners in addition, reported of $46.7 \%$ of "little progress" in the grammatical accuracy of their written works. Further $37.8 \%$ said that they made "no progress" and also $11.1 \%$ expressed they made "some progress".

The last mismatch was indicative of a split between EFL instructors and EFL learners on teacher written corrective feedback, as mentioned earlier regardless of all intervening factors as individual differences, philosophies, amount of motivation, etc, it seems with the current trend each side is heading its own way. But in any event, as Leki (1991) stressed, this can work well against the motivation of learners. Table 4.14 showed the students' and teachers perceptions on the effectiveness of teachers' feedback practices yet to better illustrate the overall mismatch between students' and teachers' perception on the effectiveness of teachers' feedback practices, Figure 2 is better presents the division below.

In the fourth research question however, this overall effectiveness of students' grammatical progress and teachers' own views toward their current in-class written feedback practices will be further analyzed through teachers' real performances on the error correction task which will be supplemented to the survey question posed and compared in the above discussion.

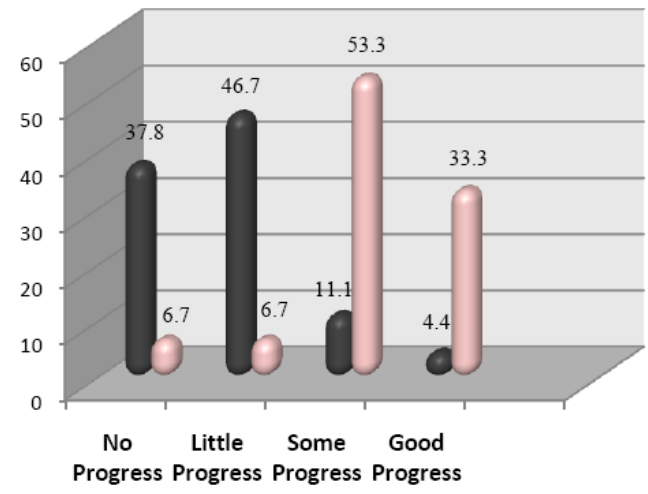

Figure 2. Mismatch between perceptions of students and teachers of feedback responsibility of teachers ( $\mathbf{Q}$ Students Teachers)

\section{Content analysis of the open-ended questions on the teacher questionnaire}

On the teacher questionnaire two open-ended questions were posed, first one at the beginning of the questionnaire targeting the main purpose of providing feedback on students' errors in students' written work and the second one addressing teachers' concerns and problems regarding providing feedback on students' writings. Here the common answer categories are presented pertaining to each open-ended question. On the first question majority of teachers (twelve out fifteen) that is $80 \%$ of them almost stated the main purpose of feedback provision on students' written errors is to make them "conscious" or "aware" of their errors. At the same time two other teachers (13.3\%) believed make students never "repeat the same error" in the future. Furthermore, one teacher $(6.7 \%)$ stated "this gives them courage to write and self-correct errors for themselves". On the second question also almost half of the teachers (53.3\%) reported of over-dependence of learners on teachers for receiving corrective feedback and called for a reduction in their role as feedback provider. Still $26.7 \%$ that is four teachers complained about inaction of learners after receiving their feedbacks that is in terms of the revision processes. Finally three teachers $(20 \%)$ doubted effectiveness of their feedback practices as their learners repeat errors on other writing tasks and topics.

\section{B. Answer to the Second Research Question}

\section{Preliminary requirements}

To provide an answer to this research question, which investigated the misfits between EFL teachers' perceptions of their written corrective feedback and their real practices in the classroom, five measures were taken: (1) teacher questionnaire data were went through frequency count analysis, (2) the 4 enclosed questions on the real error correction task (error correction task questionnaire) were collected and their frequency was calculated, (3) students' perception of teachers' practices on the related areas was collected and compared, (4) teachers marked the actual error correction task then all of its possible errors were identified and categorized and finally (5) all data were analytically compared to provide an answer to the research question. Further as explained in the previous section, teachers' answers to the enclosed questions (however they happen at the same time) were compared to their actual performance on the error correction task and their previously expressed perceptions on the teacher questionnaire to better discover areas of misfit. This was due to the limited scope of the questions tagged on the error correction task as with other studies, five major areas of feedback perception and practices underwent frequency count as to determine the misfits between teachers' perceptions and real practices on written error feedback.

Here also results reported of four areas of misfit including: (1) manner of marking (comprehensive vs. selective) (2) manner of feedback provision (direct vs. indirect) (3) use of error codes (4) amount of selected errors.

As with third research question results, accordingly, results of the fourth research questions are presented below:

Comprehensive vs. Selective

On the first question after completion of marking of the error correction task teachers were asked about their performance on their manner of feedback provision whether they did the marking comprehensively (marking all error, 
whatever the type) or they selectively did it. The results showed that on marking comprehensively 6 out of fifteen teachers meaning $40 \%$ marked all errors on the correction task. Back to teacher questionnaire data $66.7 \%$ of teachers had already expressed they mark all errors in students' assignments (comprehensively), here also $26.7 \%$ on the teacher questionnaire they had held that their marking was selective. However, error correction task questionnaire showed that 9 out of the fifteen teachers, $60 \%$ this time believed that their marking was selective. This is also in contrast with students' perception of their teachers' using comprehensive feedback on the student questionnaire and also in line with students' perception of their teachers' practices where $66.7 \%$ of them disagreed that their teachers circle or underline all of their errors. Therefore the mismatch area is clear enough. But it seems this coordination between students' perception and the results of the error correction task is expressive of the significantly important stance of EFL learners in the context of the classroom so, it is better for teachers to receive feedback on their feedback practices to modify their methods and better adjust them to learners' perceptions and preferences for it. As shown although Tables 9, 10 and 11 show the result of the teachers' real feedback behavior on the error correction task, their perception and students' preference for their teachers' practices on teachers' comprehensive vs. selective marking manner.

TABLE 9

RESULTS OF SELECTIVE VS. COMPREHENSIVE PERFORMANCE ON ERROR CORRECTION TASK

\begin{tabular}{|l|l|}
\hline Teachers & Percentage $(\%)$ \\
\hline Comprehensive & $(6) 40 \%$ \\
\hline Selective & $(9) 60 \%$ \\
\hline
\end{tabular}

TABLE 10

TEACHERS' SELECTIVE VS. COMPREHENSIVE PERCEPTION ON TEACHER QUESTIONNAIRE

\begin{tabular}{|l|l|}
\hline Teachers & Percentage $(\%)$ \\
\hline Comprehensive & $66.7 \%$ \\
\hline Selective & $26.7 \%$ \\
\hline
\end{tabular}

TABLE 11

STUDENTS’ PERCEPTION OF TEACHERS' SELECTIVE AND COMPREHENSIVE MARKING

\begin{tabular}{|l|l|}
\hline Students & Percentage (\%) \\
\hline Comprehensive & $15.6 \%$ \\
\hline Selective & $40 \%$ \\
\hline
\end{tabular}

What makes it more intersting is that, although there is a mismatch between teachers' and students' perception about teachers' manners of marking, there also exists a perfect harmony between students' perefrence and teachers' perception of their marking practices as $66.6 \%$ of students stated that they best liked all of their errors marked (Comprehensive) just like $66.7 \%$ of teachers who perceived of their practice as being more comprehensive. But what disturbed this all-out balance were teachers' practices.

Direct versus Indirect error feedback

As different strategies were used in utilizing both direct and especially indirect error feedback, on the teacher questionnaire, 6 questions altogether covered it. Therefore, results of detailed feedback strategies under each manner of feedback provision (Direct vs. Indirect) are presented and these two manners of feedback provision will be compared on the teacher questionnaire and the error correction task with each other to determine precise areas of mismatch properly.

On the first direct feedback strategy which involved circling or underling the errors and presenting the correct form of them, $66.7 \%$ had agreed that they make use of it on the teacher questionnaire. Their performance on the error correction task also indicated that $60 \%$ (nine out of fifteen) used such direct feedback provision strategy which reports of no considerable mismatch. But on the second direct feedback strategy which was coded direct feedback, where errors had to be circled or underlined and categorized with the help of a marking code there was a clear mismatch as on the questionnaire only $40 \%$ of teachers had stated they use it but it was found out $73.3 \%$ of them used it in the error correction task. As to indirect feedback strategies, fist strategy was circling or underlining without correcting (uncoded indirect feedback), $20 \%$ had held on the teacher questionnaire they apply it to students' writings, when analyzed, in the error correction task, it was also revealed $26.7 \%$ of them had used it in their real feedback practices which is expressive of no considerable mismatch. In addition, as to the second indirect feedback strategy which was to find out whether teachers use coded indirect feedback or not, $66.7 \%$ had disagreed, on the teacher questionnaire, using it and only $26.7 \%$ agreed on it. But in the error correction task 53.3\% of the teachers utilized it at least once for "verb form" or "spelling" errors which reports of a mismatch area in this regard. Third and fourth strategies were about giving uncoded and coded indirect feedback in the margin of a specific line that contained an error. Here, there was no split between teachers' perception and their real practices on the error correction task since $73.4 \%$ and $66.7 \%$ respectively, on the questionnaire disagreed using them further when analyzed, in the error correction task, $80 \%$ and $60 \%$ of the teachers respectively did not apply them to the error correction task.

Subsuming all these 6 strategies under two broad categories of direct and indirect manners of feedback provision, it was found out that $60 \%$ ( 9 out of fifteen) of the teachers on the whole, on the teacher questionnaires had stated that they give different kinds of direct feedback on students' written assignment and 40\% (6 out of fifteen) believed they provide indirect error feedback to their students' written works. This was almost supported by the teachers' actual practice one the error correction task where $53.3 \%$ of teachers (eight of fifteen) used and direct feedback strategies and $46.7 \%$ used 
indirect feedback strategies. Table 12 shows mismatch areas between the teachers' two direct and indirect strategies and teachers' practices on those two direct and indirect error feedback. Generally when these six strategies were subsumed under the two major categories of direct and indirect error feedback, on average, there appeared to exist no considerable mismatch between teachers' perception and their real practices on direct and indirect error feedback which indicated what teachers did in the error correction task ran in parallel with what they had previously stated on the teacher questionnaire. Table 13 also presents the overall result of the between teachers' perception and practices in using direct and indirect feedback.

TABLE 12

MISMATCH AREAS BETWEEN TEACHERS' PERCEPTION OF TWO OF DIRECT AND INDIRECT STRATEGIES

\begin{tabular}{|l|l|l|}
\hline $\begin{array}{l}\text { Teachers' perception of Their } \\
\text { feedback types }\end{array}$ & Percentage of teachers agreed (\%) & $\begin{array}{l}\text { Percentage of errors in error correction } \\
\text { task marked (\%) }\end{array}$ \\
\hline Coded direct feedback & $40 \%$ & $73.3 \%$ \\
\hline Coded indirect feedback & $26.7 \%$ & $53.3 \%$ \\
\hline
\end{tabular}

TABLE 13

COMPARISON BETWEEN TEACHERS' PERCPTION AND REAL PRACTICES IN USING DIRECT AND INDIRECT FEEDBACK

\begin{tabular}{|l|l|l|}
\hline Teachers & Perception (\%) & Real practices (\%) \\
\hline Direct feedback & $53.3 \%$ & $66.6 \%$ \\
\hline Indirect feedback & $46.7 \%$ & $55 \%$ \\
\hline
\end{tabular}

Use of error codes

Fourth question in the error correction task examined whether the participating teachers used error codes while marking the error correction task or not. Prior to error correction task, $60 \%$ of teachers had strongly disagreed and $13.3 \%$ disagreed, on the teacher questionnaire, that they use a marking code in marking their students' written assignments, when again asked at the end of the semester $73.3 \%$ (eleven out of fifteen) of them right after completion of the error correction task expressed that on the composition they used a marking code. Also when further their error correction task was checked and compared with their responses on the error correction task, it was revealed that they had used at least one marking code, 5 out of these eleven teachers specially used "Sp" (in line 6 of the error correction task for the wrongly written word "effisiency") while marking students, still others used "Adj" for adjective errors (occurred in line 15 of the error correction task for the wrongfully used word "good") and "Adv" for the errors in using adverb correctly (appeared in line 15 of the error correction task for the wrongfully used word "well").

Given students' perception of their teachers' practices on the student questionnaire where $51 \%$ had agreed that their teachers use error codes while marking their written works, and even $6.7 \%$ strongly agreed on the fact that their teacher do practice error codes in their writing away from being suggestive of a sharp mismatch between EFL teachers' perception and their real practices in the classroom context is indicative and illuminating in two ways: (1) Taking students' perception helps the context of the classroom improve by bridging the gap between learners preferences and expectations and teachers' strategic plans and methods of providing feedback on students' written assignments and (2) is further expressive of the fact that the learning environment is not only designed for students to learn but teachers as well should be aware of the learning context and educate themselves through teacher training courses. Such a mismatch further shows that not only teachers were not aware of their own practices or but also they even practiced something that they did not believe in. Figure 3 indicate the comparison between teachers' perception, their real practices on the error correction task and students' perception of teachers' practice in this respect.

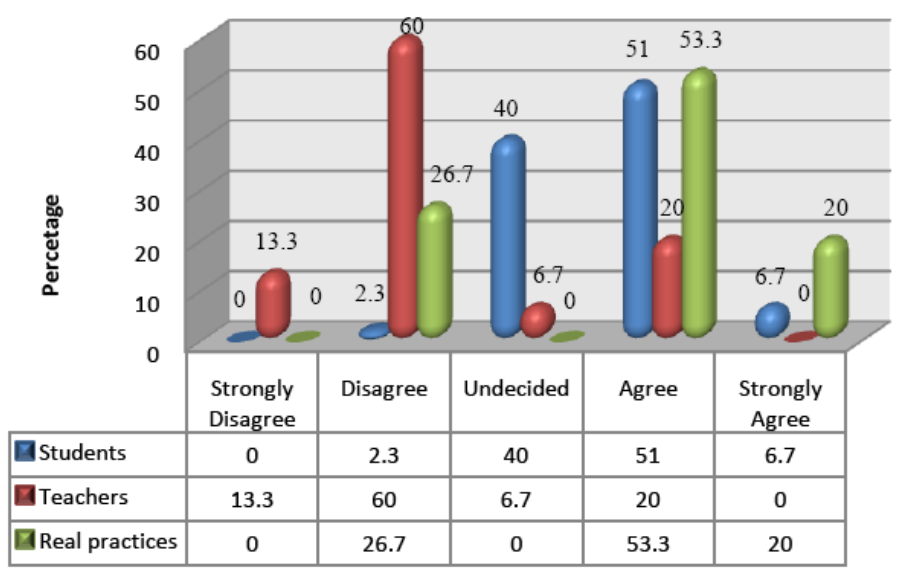

Figure 3. Comparison between teachers' perception, their real practices on error correction task and students' perception of teachers' error codes

\section{Amount of selected errors}

As with teacher questionnaire, on the error correction task teachers were asked about the amount of errors they marked in the error correction task. Those who had previously stated on the first question that they marked the sample 
composition selectively had to respond to this question however. When on the teacher questionnaire $13.3 \%$ had stated that they select about $1 / 3$ of all errors, on the error correction task it was revealed none of them $(0 \%)$ had marked such amount of errors. Further, $6.7 \%$ of teachers had expressed on the teacher questionnaire that they mark around 2/3 of all errors; here on error correction task $80 \%$ of teachers seemed to mark approximately $2 / 3$ of all errors. Also on the teacher questionnaire it was asked whether teacher mark more than $2 / 3$ of all errors which had 1 follower, that is, $6.7 \%$ which accorded harmonically with the one teacher $(6.7 \%)$ that marked the error correction task. In any event, this mismatch between teachers' perception and their delayed error correction behavior as with previous item under-study, is well expressive of teachers' having no clear idea for the provision of feedback on errors on students' written works and they are not also aware of their amount of error correction. And further this amount is in agreement with their students' expectation and perception of error feedback they demand or not. Rationally speaking, it can be said, such a mismatch on the amount of students' error on their writings can further promote a context of suspicion and mistrust among learners as this may affect their accurate estimation of their progress in grammatical accuracy of their writing skills. The interesting fact is that even most of these teachers, asserted as shown in the first dichotomy of selective and comprehensive, they had marked errors comprehensively whereas it was here rejected altogether. Table 14 presents the mismatch between teachers' perception and their real practice on the amount of the errors they select for marking.

TABLE 14

TEACHERS' PERCEPTION AND THEIR REAL PRACTICE ON THE AMOUNT OF SELECTED ERRORS

\begin{tabular}{|l|l|l|l|}
\hline Teachers & $1 / 3$ of errors $(\%)$ & $2 / 3$ of errors $(\%)$ & More than 2/3 of errors $(\%)$ \\
\hline Teachers' perception & $13.3 \%$ & $6.7 \%$ & $6.7 \%$ \\
\hline Error correction task & $0 \%$ & $80 \%$ & $6.7 \%$ \\
\hline
\end{tabular}

\section{Content analysis of the oral interview}

In the interview session as explained in methodology section, all fifteen teachers were asked 10 questions meanwhile an outline of their expressed ideas was written down and just as with open-ended questions on the questionnaire common views got clustered under unified categories. On question number one as with questionnaire data they mostly believed they had comprehensively marked the error correction task, also as to the second question they rightly mentioned underlining and circling and using a cross $(x)$ close to those faulty forms which should be omitted altogether. Yet as to the third questions majority of teachers expressed they mark errors on ad hoc basis. They also unanimously believed however indirect error feedback encourages students to self-correct their errors but they mostly go for direct feedback as they have always traditionally done it in the past. As to error codes teachers believed as they use it only for significant errors they were not aware of it due to their irregular and unsystematic use. On questions six and seven most teachers said at beginning levels it is more on teachers' shoulder to locate and correct but at higher levels up to the advanced ones it passes to students however teacher should still lead them. The same kind of concerns as with openended questions on the questionnaire were expressed which mainly focused on students' inaction in "revision" processes. On training for error correction however, they seemed to resist it but implicitly there was a call for more educational training and correction framework. Lastly they called for more students' participation and cooperation as that is the best way to share the burden and more actively engage students in the correction process which they suggested could be the best way of error correction.

\section{CONCLUSION}

The current research within the context of error feedback was probably the initial or among the initial studies to take three key sides of the written error feedback as it takes place within Iranian EFL classroom contexts. These three edges, namely learners' perception, teachers' perception and teachers' real practices were added, however, many other teacher and student variables due to introduction of many more confounding variables have not been accounted for (as highlighted in many studies), since it could hugely affect complexity of the results thus this study concordantly in and by itself tried to follow one of the pivotal features of modern approaches to language research (see Dörnyei, 2007).

Compared with Lee's 2004 and 2009 studies, It was shown about half of teachers had accurate correction of their marked errors which is in line with Lee's 2004 study. On the manner of error marking, a majority of teachers had already had held they mark all students' errors (comprehensive) which was - however, in accord with students' preferences - in contradiction with their real practices. This could create an atmosphere of dissatisfaction for learners as well as confusion for teacher if gone unheeded. But in any event, students can get frustrated and give up their writing motivation at the end. On the manner of feedback provision of course, there was no sharp misfit except for one part that is coded direct and indirect feedback, it generally pertains to the next item that is teachers' unawareness of their practice and their unconscious use of error codes on ad hoc basis at least once for, to their views, significant errors. Still as to the next misfit, not only comprehensive teachers did not go for all errors but as with Lee' (2004) study, selective teachers did not go for the amount of errors they had stated on the teacher questionnaire. But all previous mismatches aside, when teachers' feedback effectiveness was explored from three sides that is, learners, teachers themselves and their real performance on error task; it was revealed all previous mismatch manifested them in this last one as teachers did not practice most of the things they asserted to. Further as mentioned earlier this is possibly of teachers' ignorance to four things: (1) students' perceptions and preferences, (2) learning context, (3) their own beliefs and (4) new developments in 
language teaching (that is to say, they showed disregard for their students' perception) which supports active role of learners and the learning context in general and what make it worse is that teachers turn their backs to achievements in the area of second or foreign writing research in particular.

Interestingly, this study also showed many differences between teachers' asserted error correction practice and learners' preferences. A vast majority of teachers mark errors selectively, but on the contrary, a large majority of students prefer comprehensive one, for instance. In fact, students' expectations and preferences may be easily affected by teachers' practices. Also several areas of misfit were found between teachers' perception of their feedback activities and their actual feedback behavior. If all the time in students' language learning process their EFL instructors mark their errors comprehensively and presented the correct forms to them, learners as Lee (2004) maintained "may feel that these are the right things to do and that it is the teacher's job to correct errors". Without altering teachers' philosophies and their actual practices, it is not feasible that learners reformulate their expectations, as students' preferences and perceptions are often molded or highly influenced by their instructors' actual practices. Therefore, it is, as alluded to by some feedback researchers, raising awareness about harmful impact of comprehensive error marking should be incorporated into language programs. It is also of paramount importance that EFL instructors take required measures to morph learners into autonomous editors through less direct interventions.

\section{APPENDIX A THE ERROR CORRECTION TASK (Please correct the following composition)}

Been anxious is not useful for everybody in his or her life.

There are some tips for everybody to reduce anxiousness in his or her life.

(5) 1. First, Relax. If you are anxious, you can't doing everything well and your effisiency would be reduced.

2. Second, Self-confidence. If you are confidence to do everything, you can overcome your anxiousness about your problems in life.

(10) 3. Have hope for the future. This is so important to reduce your anxiousness. Having hope makes a great energy so you can do everything that you want.

4. Have confidence in other people. You have to think; that other people are not your enemy.

(15) 5. Eating good. If your nourishment is not well you be nervous to do everything. There are some interesting foods that makes everybody happy. Like ice-cream and spaghetti.

These tips make you happy and won't make you (20) anxious about everything in your life.

1- In this error correction task I have marked (please tick).
a) All errors
b) Selectively

2- Approximate percentage of errors I marked were about (please tick).
a) $1 / 3$
b) $2 / 3$
c) more than $2 / 3$

3- My criteria for error selection was:-

4- Did you use a marking code in this error correction task?

\section{REFERENCES}

[1] Belanoff, P., \& Dickson, M. (eds.). (1991). Portfolios: process and product. Portsmouth, NH: Heinemann.

[2] Brandl, K. (1995). Strong and weak students' preferences for error feedback. Modern Language Journal, 79(2), $194-211$.

[3] Brown, H. D. (2007). Principles of language learning and teaching (5th ed.). New York: Pearson Education.

[4] Caulk, N. (1994). Comparing teacher and students responses to written work. TESOL Quarterly, 28, 181-188.

[5] Cohen, A. (1987). Student processing of feedback on their compositions. In A. L. Wenden \& J. Rubin (Eds.), Learner strategies in second language learning (pp. 57-69). Englewood Cliffs, NJ: Prentice-Hall.

[6] Cohen, A. \& Cavalcanti, M. (1990). Feedback on compositions: Teacher and student verbal reports. In M. Long \& J. Richards (Series Eds.) \& B. Kroll (Vol. Ed.), Second language writing: Research insights for the classroom (3rd ed.). New York: Cambridge University Press.

[7] Conrad, S. M., \& Goldstein, L. M. (1999). ESL students revision after teacher-written comments: Text, contexts, individuals. Journal of Second Language Writing, (8), 147-180.

[8] Dörnyei, Z. (2003). Questionnaires in Second Language Research: Construction, Administration, and Processing. University of Nottingham. Lawrence Erlbaum Associates publishers. Mahwah, New Jersey.

[9] Dörnyei, Z. (2007). Research Methods in Applied Linguistics. New York: Oxford University Press.

[10] Eskey, D. E. (1983). Meanwhile, back in the real world ... Accuracy and fluency in second language teaching. TESOL Quarterly, 17, 315-323.

[11] Ferris, D. (1995). Student reactions to teacher response in multiple-draft composition classrooms. TESOL Quarterly, 29, 33-35.

[12] Ferris, D. R., \& Roberts, B. (2001). Error feedback in L2 writing classes: How explicit does it need to be? Journal of Second Language Writing, 10, 161-184.

[13] Ferris, D. (2002). Responding to student errors: Issues and strategies. In D. Ferris (Ed.), Treatment of error in second language student writing (pp. 49-76). Ann Arbor, MI: The University of Michigan Press.

[14] Ferris, D. (2003). Response to student writing: Implications for second language students. Mahwah, NJ: Lawrence Erlbaum.

[15] Frantzen, D. (1995). The effects of grammar supplementation on written accuracy in an intermediate Spanish content course. Modern Language Journal, 79, 329-344.

[16] Glaser, B. (1978). Theoretical sensitivity. Mill Valley, CA: Sociology Press. 
[17] Glaser, B. G. (2001). The grounded theory perspective: Conceptualization contrasted with description. Mill Valley, CA: Sociology Press.

[18] Glaser, B. G., \& Holton, J. (2004). Remodeling Grounded Theory. Qualitative Social Research, 5(2), 1-17.

[19] Glaser, B. G., \& Strauss, A. L. (1967). The discovery of grounded theory: Strategies for qualitative research. Chicago: Aldine.

[20] Hamp-Lyons, L., \& Condon, W. (2000). Assessing the portfolio: principles for practice, theory and research. Cresskill, NJ: Hampton Press.

[21] Hedgcock, J., \& Lefkowitz, N. (1996). Some input on input: Two analyses of student response to expert feedback in L2 writing. The Modern Language Journal, 80, 287-308.

[22] Horowitz, D. (1986). Process not product: Less than meets the eye. TESOL Quarterly, 20, 141- 144.

[23] Hyland, K. (1990). Providing productive feedback. ELT Journal, 44(4), 279-285

[24] Komura, K. (1999). Student response to error correction in ESL classrooms. Unpublished master's thesis, California State University, Sacramento.

[25] Krashen, S. (1981). Second language acquisition and second language learning. Oxford: Pergamon Press.

[26] Lalande, J. F. (1982). Reducing composition errors: An experiment. Modern Language Journal, 66, 140-149.

[27] Lee, I. (1997). ESL learners' performance in error correction in writing: Some implications for teaching. System, 25, 465-477.

[28] Lee, I. (2003). L2 writing teachers' perspectives, practices and problems regarding error feedback. Assessing Writing, 8, 216237.

[29] Lee, I. (2004). Error correction in L2 secondary writing classrooms: The case of Hong Kong. Journal of Second Language Writing, 13, 285-312.

[30] Lee, I. (2008). Understanding teachers' written feedback practices in Hong Kong secondary classrooms. Journal of Second Language Writing, 17, 69-85.

[31] Lee, I. (2009). Ten mismatches between teachers' beliefs and written feedback practice. ELT journal, 63, 13-22.

[32] Leki, I. (1990). Coaching from the margins: Issues in written response. In B. Kroll (Ed.), Second language writing: Research insights for the classroom (pp. 57-68). Cambridge: Cambridge University Press.

[33] Leki, I. (1991). The preferences of ESL students for error correction in college-level writing classes. Foreign Language Annals, 24, 203-218.

[34] Montgomery, J. L., \& Baker, W. (2007). Teacher-written feedback: Student perceptions, teacher self assessment, and actual teacher performance. Journal of Second Language Writing, 16, 82-99.

[35] Muncie, J. (2000). Using written teacher feedback in EFL composition classroom. ELT Journal, 54(1), 47-53.

[36] Purves, A. C. (1992). Reflections on research and assessment in writing compositions. Research in the Teaching of English, 26(1), 106-122.

[37] Radecki, P., \& Swales, J. (1988). ESL student reaction to written comments on their written work. System, 16, 355-365.

[38] Raimes, A. (1985). What unskilled ESL students do as they write: A classroom study of composing. TESOL Quarterly, 19, 229-258.

[39] Reid, J. (1994). Responding to ESL students' texts: The myths of appropriation. TESOL Quarterly, 28, $273-292$.

[40] Rennie, C. (2000). Error feedback in ESL writing classes: What do students really want? Unpublished master's thesis, California State University, Sacramento.

[41] Richards, J. C., \& Rogers, T. S. (2001). Approaches and methods in language teaching: A description and analysis. Cambridge: Cambridge University Press.

[42] Robb, T., Ross, S., \& Shortreed, I. (1986). Salience of feedback on error and its effect on EFL writing quality. TESOL Quarterly, 20, 83-93.

[43] Saito, H. (1994). Teachers' practices and students' preferences for feedback on second language writing: A case study of adult ESL learners. TESL Canada Journal, 11(2), 46-70.

[44] Semke, H. (1984). The effects of the red pen. Foreign Language Annals 17, 195-202.

[45] Truscott, J. (1996). The case against grammar correction in L2 writing classes. Language Learning, 46, 327-369.

[46] Truscott, J., \& Hsu, A. (2008). Error correction, revision, and learning. Journal of Second Language Writing, 17, $292-305$.

[47] Warschauer, M., Turbee, L., \& Roberts, B. (1996). Computer learning networks and student empowerment. System, 24, 1-14.

[48] Zamel, V. (1982). Writing: The process of discovering meaning. TESOL Quarterly, 16,195-209.

[49] Zamel, V. (1985). Responding to student writing. TESOL Quarterly, 19, 195-202.

Reza Norouzian has been graduated in TEFL from University of Tehran; he currently runs "EAP" courses at the University of Tehran, Tehran University of Medical Sciences and other academic courses at the English department of the Azad University. His main areas of interest are Written Corrective Feedback (WCF), Qualitative EFL research and CALL (Computer-Assisted Language Learning). His all-new book is at its final stage.

Ali Akbar Khomeijani Farahani received his B.A. in the English Language and Literature from the University of Tehran. He got his M.A. and Ph.D. in Linguistics from Leeds University. He is currently a faculty member at the University of Tehran. His re search interests are Syntax, Discourse Analysis, and TBLT. He has been teaching Linguistics and English for more than 19 years. 